\title{
CUANDO LOS JUECES DECLARAN \\ INCONSTITUCIONAL LA CONSTITUCIÓN: \\ LA REELECCIÓN PRESIDENCIAL EN AMÉRICA LATINA \\ A LA LUZ DE LAS ÚLTIMAS DECISIONES DE LAS \\ CORTES CONSTITUCIONALES
}

\section{When judges declare Constitution as unconstitutional: Presidential reelection in Latin-American according to the last decisions of the Constitutional Courts}

\author{
ROBERTO VICIANO PASTOR' \\ Universidad de Valencia \\ roberto.viciano@uv.es \\ GABRIEL MORENO GONZÁLEZ² \\ Universidad de Valencia \\ Gabriel.Moreno-Gonzalez@uv.es
}

Cómo citar/Citation

Viciano Pastor, R. y Moreno González, G. (2018).

Cuando los jueces declaran inconstitucional la

Constitución: la reelección presidencial en América

Latina a la luz de las últimas decisiones de las Cortes Constitucionales.

Anuario Iberoamericano de Justicia Constitucional, 22, 165-198.

doi: https://doi.org/10.18042/cepc/aijc.22.06

\section{Resumen}

El presente artículo tiene por objeto el análisis crítico de las decisiones tomadas por varios tribunales supremos o constitucionales de Latinoamérica que han

\footnotetext{
1 Catedrático de Derecho Constitucional de la Universitat de València y titular de la Cátedra Jean Mannet.

2 Investigador de derecho constitucional de la Universitat de València.
} 
permitido la reelección presidencial a pesar de la existencia, explícita, de su prohibición en la Carta Magna. La inaplicabilidad de previsiones constitucionales que han acordado, al considerarlas paradójicamente como «inconstitucionales», se sustenta en lo que los autores creen que es una confusión doctrinal y una errónea interpretación de categorías teóricas inadecuadas, en el marco, además, de la asunción hipertrofiada de funciones impropias a la naturaleza y fines de la justicia constitucional.

\section{Palabras clave}

Reelección presidencial; justicia constitucional; Convención Interamericana de Derechos Humanos; neoconstitucionalismo; limitación de mandatos.

\section{Abstract}

This article contains a critical review of the decisions that some Latin-American Supreme or Constitutional Courts have made allowing presidential reelection despite the explicit ban in the Constitution. According to the authors, the inapplicability of constitutional provisions, which have been declared as "unconstitutional" by Courts, derives from academic misunderstanding and wrong interpretations on inadequate categories. Due to this fact, Courts have assumed an improper and hypertrophied function beyond the nature and objectives of constitutional justice.

\section{Keywords}

Presidential reelection; constitutional justice; American Convention on $\mathrm{Hu}-$ man Rights; neoconstitutionalism; mandate limitation. 


\section{SUMARIO}

I. LA PROBLEMÁTICA DE LA REELECCIÓN PRESIDENCIAL EN AMÉRICA LATINA. II. COSTA RICA 2003: UN CONTROVERTIDO CONTROL DE LA REFORMA CONSTITUCIONAL. III. NICARAGUA 2009: EL IMPULSO DE UNA NUEVA TENDENCIA JURISDICCIONAL. IV. HONDURAS 2015: LA REELECCIÓN COMO PROBLEMA CENTRAL DE LA CONSTITUCIÓN. V. BOLIVIA 2017: EL TRIBUNAL CONSTITUCIONAL CONTRA LA VOLUNTAD DE LOS CIUDADANOS. VI. ¿̇NORMAS CONSTITUCIONALES INCONSTITUCIONALES?: 1. El pretendido «derecho humano» a la reelección o la utilización torticera del control de convencionalidad. VII. CONCLUSIÓN. BIBLIOGRAF́́A.

\section{LA PROBLEMÁTICA DE LA REELECCIÓN PRESIDENCIAL EN AMÉRICA LATINA}

La primera legislación escrita que se ha conservado de la antigua Grecia procede de Dreros, en Creta, probablemente del 650 a. C, y limitaba el desempeño prolongado indebidamente de las principales magistraturas de la ciudad con el objetivo de evitar toda tiranía (Lane Fox, 2007: 100). Si el objeto tradicional del derecho constitucional, y aun del derecho en sí, ha sido el control y juridificación del poder político, no nos ha de extrañar que una de las constantes preocupaciones del mismo haya sido la limitación temporal de su ejercicio. Por ello, la ingeniería constitucional se ha volcado en la articulación de un sistema pretendidamente eficaz que evite la acumulación de poder y los efectos, adversos, que su prolongación en las mismas manos suele conllevar.

En esta lucha de siglos por la racionalización del poder político, y tras su superación personalista por la abstracción del Estado moderno (Requejo Pagés, 2016), se produce una temprana línea divisoria entre América y la vieja Europa (Blanco Valdés, 2006). En los albores del constitucionalismo y del liberalismo, el continente americano verá crecer en su seno una nueva República, Estados Unidos, que constituirá uno de los ejemplos más innovadores de la limitación, constitucional, de un poder político que, a diferencia de Europa, hundirá la legitimidad de todos sus estamentos en la voluntad popular (aunque fuera de manera limitada). Por el contrario, al otro lado del Atlántico los esfuerzos democratizadores y la conquista paulatina de las libertades, en 
un inicio solo protagonizados por la burguesía, tendrán como obstáculo permanente a las anquilosadas estructuras ejecutivas de las monarquías. En estas, por su propia naturaleza, no cabía ni cabe regulación alguna de los mandatos, y su antagonismo con la institución de la asamblea, donde se concentrarán los avances democráticos, hará progresivamente parlamentarios a los sistemas constitucionales europeos. El Gobierno, poco a poco desgajado del monarca, derivará su legitimidad del capricho cambiante de las Cámaras, verdaderas protagonistas del nuevo orden constitucional y reacias, per se, a la personalización de todo poder.

En cambio, el presidente en Estados Unidos, asumiendo parte de las atribuciones y potestades tradicionalmente reales, sí será visto como un cargo que, por su raigambre democrática, no solo permitiría la alternancia, sino que la haría deseable. Es clásica la mención al discurso de despedida en 1796 de George Washington, primer presidente de EE. UU. y padre fundador, donde ya alerta del peligro de que el Estado se personalizara, y donde, con un virtuosismo de estilo inconfundible, expone los motivos de su temprana retirada de la más alta magistratura tras dos mandatos consecutivos.

El ejemplo de Washington, timbrado en su discurso, y el temor a lo monarquizante, que siempre impregnó las intervenciones de los Founding Fathers (Ellis, 2002), hicieron del límite temporal de dos mandatos una convención constitucional no escrita ni recogida en la Carta Magna, pero deseable en su respeto y en la garantía de su funcionalidad republicana. Convención que sería, además, respetada escrupulosamente hasta la presidencia de Roosevelt, cuando los embates de la guerra mundial y la popularidad del presidente en medio de la crisis económica que había asolado al país le granjearon el apoyo del pueblo norteamericano para, incluso, más de tres mandatos. Su temprana muerte, sin embargo, "posibilitó» que, tras dicha experiencia, se llevara finalmente a la Constitución la limitación absoluta de dos mandatos con la aprobación, en 1947, de la vigesimosegunda enmienda (ratificada en 1951).

Esta mayor personalización del poder político respecto de Europa que se da ya en los primigenios Estados Unidos se repetirá, con más intensidad si cabe, en la práctica totalidad de los nuevos Estados surgidos de la América española. Desde tiempos precolombinos y, por supuesto, durante el largo período colonial, las formas de poder latinoamericanas estarán presididas por una alta concentración y centralización, debidas no solo a las concepciones entonces reinantes, sino también a las características naturales y geográficas propias de una región de magnitudes inconmensurables. En el momento de la independencia de los primeros territorios españoles de ultramar el más cercano ejemplo de república libre que existía era el de la presidencialista Norteamérica, dada la mayoritaria pervivencia monárquica bajo sus múltiples formas en Europa; modelo este del que, precisamente, se separaban las élites liberales 
de las incipientes naciones. El presidencialismo estadounidense será la referencia en una región con una tradición caudillista (Martínez Sospedra, 2011: 141-173) y donde los militares, nada dados al pluralismo y a la abstracción de la autoridad, tendrán la batuta desde los primeros estadios de las independencias. Uruguay, Chile o Brasil tendrán a lo largo de las últimas dos centurias períodos momentáneos de tímido parlamentarismo, pero nunca logrará triunfar y consolidarse. Perú, por su parte, constituirá casi siempre un caso extrañamente raro al presentar una especie de presidencialismo parlamentarizado y debilitado por un sistema de pesos y contrapesos un tanto sui generis (García Belaunde et al., 2017: 9-24).

Fuera de tales momentos y excepciones, la nota dominante fue y sigue siendo hoy el presidencialismo, una forma de gobierno que en el continente ha venido acompañada, en muchas ocasiones, de tendencias caudillistas cuando no, directamente, de verdaderas dictaduras unipersonales. «Mucho gobierno y poco Estado", en referencia a la ausencia de un Estado de derecho firme que limite la autoridad de los respectivos Ejecutivos, es un aforismo que puede predicarse de no pocos sistemas políticos latinoamericanos, donde la crítica al hiperpresidencialismo por autores como Linz ha abierto la puerta a una reformulación, al menos teórica, de la conveniencia o no de tales sistemas (Linz, 1990: 51-60; 1994: 3-87). No es lugar este para ahondar en tales debates, sin duda enriquecedores, pero sí habría que hacer notar ciertas paradojas que se dan en los argumentos de los más férreos críticos del presidencialismo latinoamericano. $Y$ es que, acusado de ser un injerto de otro sistema (el estadounidense) y no adecuarse a las verdaderas necesidades y exigencias de los países de América Latina, no debiera ser a su vez sustituido de golpe y sin adaptación por otros modelos, como el parlamentario, también extraños a la lógica latinoamericana y propio de dinámicas históricas diferentes. Al margen de que es muy discutible que la posición del presidente del Gobierno en un sistema parlamentario sea menos fuerte que la del presidente de la República en un modelo presidencialista, pues el primero, por la propia lógica del sistema, acumula la hegemonía en el Ejecutivo y también en la mayoría del Legislativo, cosa que no siempre ocurre en el presidencialismo. De todos modos, cualquier intento de replantear los sistemas de gobierno latinoamericanos ha de partir, antes que nada, de la firme voluntad constituyente de sus pueblos y de la consiguiente experiencia atesorada. Los híbridos constitucionales surgidos de la mera acumulación por prurito técnico o generalizada imitación reverencial no suelen arrojar, precisamente, resultados óptimos (Gargarella, 2014: 97-111).

Sea como fuere, la cuestión de la personalización del poder, de su concentración y continuidad sigue siendo un problema candente en el marco de los presidencialismos latinoamericanos. Durante el siglo XX, y como quiera que en ellos los peligros mencionados se incrementaban debido a las características 
políticas de la región y a una historia decimonónica «rica» en dictaduras y regímenes autocráticos, la tendencia a la constitucionalización de férreos límites a la reelección presidencial se consolidó. El paso del liberalismo a un tímido liberalismo democrático en América Latina al amparo de la renovada fórmula de la democracia constitucional vino así, con la única excepción de Paraguay (Oría, 1995), acompañado de la restricción temporal de la máxima magistratura del Estado. Con la referencia de Estados Unidos y con los auspicios de la teoría del poder que, desde la Antigüedad, contemplaba como virtud la alternancia política, los Estados latinoamericanos en transformación creyeron encontrar en la limitación de mandatos una solución aceptable para el eterno problema del caudillismo autoritario (Treminio Sánchez, 2013: 65-70).

En los noventa, sin embargo, comenzó una ola de reformas para modificar las cláusulas absolutas de no reelección, convirtiendo estas en alternas (tras un período fuera del cargo, se puede volver a postular), continuas pero limitadas (máximo dos períodos, por ejemplo) o directamente ilimitadas. Así ocurrió, con mayor o menor éxito en tales iniciativas, en Perú en 1993 (Fujimori), en Argentina en 1994 (Carlos Menem) o en Brasil en 1999 (Fernando Henrique Cardoso). Asimismo, esta tendencia favorable a la reelección limitada encontrará buena acogida desde el comienzo en el seno del nuevo constitucionalismo latinoamericano (Viciano Pastor y Martínez Dalmau, 2011). La Constitución de Colombia de 1991, iniciadora de ese movimiento, instaurará la reelección continuada para un solo mandato, criterio que se seguirá posteriormente en Venezuela con la Constitución de 1999, y que se adoptó en las últimas de Ecuador (2008) y Bolivia (2009), sustituyendo en estos casos la reelección alterna (prohibición de continuidad) por la continua de dos períodos presidenciales (Treminio Sánchez, 2013: 70-73). Hay que destacar, no obstante, que estas constituciones, salvo la de Colombia, incorporan la novedosa revocatoria de mandato del presidente de la República, lo que permite impedir la prolongada permanencia de un presidente no deseado por la población.

A pesar de esta última tendencia apuntada, la limitación constitucional a priori sigue siendo la nota dominante en los presidencialismos latinoamericanos, y la fuerza de resistencia que las constituciones proyectan ha permitido que las cláusulas hayan podido hacer frente a los deseos de permanencia de muchos mandatarios. Sin embargo, se ha asistido también en los últimos años, con ejemplos muy recientes además, a una nueva ola de cambios constitucionales para favorecer la reelección indefinida; ola que no viene, empero, precedida de la voluntad constituyente o del ejercicio legítimo del poder de reforma constitucional. Distintos gobernantes han logrado acudir a sus respectivos órganos de justicia constitucional para declarar inaplicables o inconstitucionales, por paradójico que parezca, las prohibiciones de reelección que sus normas fundamentales expresamente establecen. En Costa Rica (2003), 
Nicaragua (2009), Honduras (2015) y Bolivia (2017), las previsiones taxativas de la Constitución en la materia se han conseguido sortear a través de sentencias cuanto menos controvertidas de los órganos que, en teoría, deberían velar por su recto cumplimiento y garantía; sentencias que ahondan el hiperpresidencialismo en los cuatro países.

Aunque podemos encontrar antecedentes claros de interferencia del Poder Judicial a favor de la reelección a pesar de la prohibición en la norma suprema, como el de Perú de 1997, no ha sido hasta los casos costarricense y nicaragüense cuando, abiertamente, una Corte ha declarado inconstitucional un precepto de la Constitución. En el Perú, los intentos por reelegirse de Fujimori finalmente lograron plasmarse en la Ley de Interpretación Auténtica, un sinsentido jurídico mediante el cual se vaciaba la prohibición constitucional de repetir más allá de dos mandatos. Llevada ante el Tribunal Constitucional, acusada de claro vicio de inconstitucionalidad, el Congreso inhabilitó a tres de sus magistrados impidiendo, con ello, el quorum necesario y dando vía libre, mediante el «sobreseimiento» acordado por los magistrados restantes (art. 4 LOTC de Perú), a la reelección del autoritario presidente para un tercer mandato en el año 2000. Las circunstancias políticas posteriores, de sobra conocidas, llevarían a una reforma constitucional antifujimorista tras las elecciones (Ley 27365), prohibiendo la reelección inmediata y circunscribiendo los mandatos a cinco años (Carpio Marcos, 2000).

\section{COSTA RICA 2003: UN CONTROVERTIDO CONTROL DE LA REFORMA CONSTITUCIONAL}

Desde la sentencia de Costa Rica, sin embargo, se ha inaugurado un ciclo ciertamente preocupante desde el punto de vista constitucional, como decíamos, y en el que las Cortes han asumido un papel constituyente que no les corresponde y donde, mediante la utilización de espurios argumentos pretendidamente jurídicos, han modificado los contenidos de las propias Constituciones que debieran hacer cumplir y, en todo caso, interpretar. El temor al caudillismo y la necesidad política de la alternancia, entendida esta como mejor antídoto frente a aquel y como salvaguarda de la pluralidad democrática, quedarían así removidos no por el deseo expreso del pueblo, verdadero constituyente y único legitimado al efecto, sino por la decisión jurídicamente endeble, tal y como ahondaremos en los siguientes epígrafes, de los jueces constitucionales. Algo que puede reforzar las críticas al hiperpresidencialismo que tanto temían los griegos de Creta o los norteamericanos de Washington, pero que parece aventurarse con fuerza en determinados sistemas 
constitucionales y que, en última instancia, puede también menoscabar la esencia democrática de estos (McConnell, 2010).

En este sentido, el caso costarricense ha de enmarcarse en el papel preponderante que la Corte Suprema, a través de su Sala Constitucional (denominada Sala IV), ha venido desempeñando en la configuración y determinación del sistema político del pequeño país centroamericano (Martínez-Barahona, 2010: 723-750). La Constitución de 1949 permitía la reelección al presidente tras un período fuera del poder, pero una enmienda constitucional de 1969 la terminaría prohibiendo totalmente (art. 132). El debate iniciado por el presidente Óscar Arias (1986-1990, 2006-2010) sobre la posibilidad de su reelección se centraría a principios de la década de 2000 en la «inconstitucionalidad» de dicha enmienda; debate que llegaría, a través de los diputados de su partido, a un intento de nueva reforma constitucional cuya tardanza, debido a las dificultades y trabas parlamentarias, alentó la interposición de un recurso ante la Corte Suprema. Mediante la Resolución 2000-7818 la Sala Constitucional rechazó, sin embargo, que la alegación de supuestas taras procedimentales en el trámite de la enmienda de 1969 pudiera ser de tal entidad como para declarar esta inconstitucional. No obstante, la perseverancia del partido de Arias llevaría de nuevo el caso ante una Corte más proclive, que en 2003, y sobre un recurso con argumentos diferentes, anularía mediante la polémica Resolución 2003-2771 la enmienda de 1969, permitiendo, con ello, la reelección de Arias.

Los argumentos esgrimidos en esta última sentencia fueron fundamentalmente dos (Romero Pérez, 2015). Por un lado, y aquí reside la diferencia principal con el resto de casos que veremos con mayor profundidad, se insiste en la sentencia en que la reforma de 1969 era inconstitucional, de fondo, por incorporar una regresión en los derechos fundamentales (el de participación política) mediante la institución de la reforma, y no del poder constituyente. Solo a este pertenece, según la Sala Constitucional de la Corte Suprema, la posibilidad de enmendar totalmente la Constitución, o de redactar una nueva, y de hacerlo regresivamente. Según la Sala, un límite sustantivo al poder de reforma se encontraría, por ende, en el principio de no regresividad, a pesar de que la Ley de jurisdicción constitucional n. ${ }^{\circ} 7135$ de 1989, que regula las funciones y atribuciones de la Sala Constitucional, impide taxativamente (arts. 73 y 76) el control material de las reformas constitucionales (Romero Pérez, 2015: 130), y a pesar, asimismo, de que la Constitución no consagra en ningún artículo el principio de no regresividad.

Por otro lado, y al igual que harán las Cortes de Nicaragua, Honduras y Bolivia, se considera en la sentencia que la prohibición de la reelección conlleva un menoscabo en los derechos fundamentales, como el de participación política (sufragio pasivo) o el de igualdad. La existencia de una disposición 
que aun teniendo rango constitucional restrinja desproporcionalmente tales derechos puede dar lugar, como así aprecia la Sala, a vicio de inconstitucionalidad debido a la presencia de una antinomia, presencia que creemos infundada, como a continuación veremos en detalle respecto a los siguientes, y similares, casos.

El grueso de la argumentación de la Sala consistió, aun así, en su pretendida facultad de controlar una reforma constitucional basándose en las limitaciones intrínsecas que dicha institución contiene. En los casos nicaragüenses (aunque aquí también hubo una reforma con parecidas características), hondureño y boliviano, el peso de la decisión ha recaído en la supuesta contradicción interna entre preceptos y en la consideración, consiguiente, de que existe una parte de la Constitución con una potencialidad jurídica mayor que el resto de previsiones. Aunque en la sentencia costarricense ya podemos encontrar perfilados los argumentos principales sobre los que recaerán las subsiguientes decisiones, la centralidad que ocupa en ella la posibilidad de controlar judicialmente la reforma constitucional le resta interés para el objeto central de este artículo, a saber, la de falta de fundamento de las declaraciones de inconstitucionalidad de normas constitucionales por la concurrencia de antinomias internas.

Sea como fuere, la anulación por parte de la Corte Suprema de la prohibición de reelección que contenía el art. 132 de la Constitución de Costa Rica permitió de nuevo la elección de Óscar Arias y su nombramiento como presidente de la República para otro mandato (2006-2010), inaugurando, como decimos, un ciclo de polémicas sentencias prorreelección que tendría su segundo paradigma en Nicaragua y que, a continuación, pasaremos a analizar con más detalle.

\section{NICARAGUA 2009: EL IMPULSO DE UNA NUEVA TENDENCIA JURISDICCIONAL}

Nicaragua, siguiendo la estela latinoamericana indicada al principio, se constituye en una República presidencialista donde el Jefe de Estado, también Jefe de Gobierno, es la figura política esencial en la que convergen las competencias más relevantes y sobre la que pivota la articulación del resto de poderes constituidos. La Constitución actualmente vigente, de 1987, ha sufrido ocho reformas y sucesivas «ampliaciones» mediante los mecanismos jurídicos de las leyes constitucionales y las leyes marco, las cuales, aun no añadiéndose al texto de la Carta Magna, la complementan en pie de igualdad, conformando, con ello, una especie de bloque de constitucionalidad sui generis. El sistema constitucional, de clara impronta sandinista y producto de las transformaciones y el 
contexto en los que este movimiento logró triunfar y consolidarse, es garantizado en última instancia por la Sala de lo Constitucional de la Corte Suprema de Justicia, encargada de velar por el recto cumplimiento de las disposiciones de la Carta Magna y cuya accesibilidad, si la comparamos con la de los países europeos o incluso de su entorno, es bastante amplia y generosa. Hay que destacar, asimismo, que ni la Constitución ni las leyes complementarias han sido nunca refrendadas por el pueblo nicaragüense, a pesar de lo cual dicen predicarse de su directa y soberana voluntad.

Ficción jurídica aparte, la Constitución prevé (aunque ya no se aplique) en sus arts. 147 y 178 la prohibición de reelección más allá de dos mandatos tanto para el presidente y el vicepresidente de la República como para los alcaldes y vicealcaldes de los municipios del país. Esta limitación de mandatos fue introducida mediante el art. 13 de la Ley n. ${ }^{\circ} 192$, de reforma parcial de la Constitución Política de Nicaragua, de 4 de julio de 1995, una de las múltiples reformas constitucionales que, como decíamos, se han producido en el sistema político nicaragüense. Sin duda, pesaría en la intención de la reforma el miedo de la oposición al continuismo y al caudillismo tras la guerra con la contra, en un contexto tradicional de falta de pluralismo político. La Constitución solo circunscribe tal limitación de mandato, sin embargo, a los cargos ejecutivos mencionados, pero no la extiende a otros de carácter representativo, como los diputados de la Asamblea Nacional o los representantes ante el Parlamento centroamericano. Tales disposiciones constitucionales son, además, taxativamente claras y no pueden dar pie, por su tenor literal, a interpretaciones espurias que desvirtúen su finalidad explícita.

No obstante, en 2009, el presidente de la República, Daniel Ortega, quien, junto con el histórico Frente Sandinista de Liberación Nacional (FSLN), había ganado las elecciones y regresado al poder a finales de 2006, interpuso un recurso ante el Consejo Supremo Electoral para que este le permitiera volver a presentarse como candidato en 2011, ya que previamente, hasta 1990, había sido presidente bajo la Constitución del 87. La fundamentación de la petición, que será la que siga también más tarde ante la Sala Constitucional, se basa en la supuesta existencia en la Carta Magna de una antinomia jurídica por la que, de un lado, se reconocería y garantizaría el principio de igualdad en y ante la ley, y, de otro, se establecería una prohibición que expresamente atentaría contra dicha igualdad y sus derechos de participación política. El recurso, no obstante, sería rechazado por el Consejo Supremo Electoral, con una argumentación harto interesante. El máximo órgano de garantía de las elecciones en Nicaragua, de mayoría sandinista, se abstendría de entrar en el fondo al decir, expresamente, que el alcance y la posibilidad de existencia de antinomias constitucionales no sería de su competencia, sino de la Corte Suprema y su Sala Constitucional, dando con ello a entender que, 
en efecto, habría una contradicción en la Norma Fundamental que podría salvarse a favor del recurrente. Con ello, Daniel Ortega y decenas de alcaldes $\mathrm{y}$ vicealcaldes de los municipios del país acudieron finalmente en amparo a la Corte alegando el menoscabo que la decisión del Consejo Supremo Electoral producía en sus derechos fundamentales.

Admitido a trámite el amparo, la Sala Constitucional emitió el 19 de octubre de 2009 la Sentencia n. ${ }^{\circ}$ 504, objeto aquí de nuestro análisis. En dicha resolución, el más alto tribunal nicaragüense hace suyos los argumentos planteados por el presidente Ortega y los alcaldes y vicealcaldes, y no solo reconoce la existencia de una antinomia constitucional, sino que resuelve esta a través de la declaración de inconstitucionalidad y, por ende, de inaplicabilidad, de la previsión constitucional recogida en los arts. 147 y 178, que establecen la limitación de mandatos. Frente a estas limitaciones, integrantes de la parte orgánica de la Constitución donde se regulan los poderes del Estado, dice la Corte que se yerguen los principios, valores y derechos fundamentales que han de informar dicha parte orgánica y que, en consecuencia, están por encima de ella. Aunque acude a multitud de artículos, incluidos los referentes a la soberanía y autodeterminación de Nicaragua, el principal aducido es el art. 48, que reza: «Es obligación del Estado eliminar los obstáculos que impidan de hecho la igualdad entre los nicaragüenses y su participación efectiva en la vida política, económica y social del país». Así, esta disposición tendría el poder por su fuerza dogmática, y de acuerdo con el razonamiento de la Corte, de anular por inconstitucional cualquier otra disposición orgánica de la propia Constitución. Es más, recuerda la Corte que ya en anteriores ocasiones había tenido que acudir a la diferencia cualitativa entre la parte dogmática y la orgánica para resolver ulteriores antinomias, como la supuestamente existente entre diversas limitaciones que establecía la Ley Electoral, de rango constitucional, y los principios y derechos generales que establecía el corpus originario de la Carta Magna (sentencia de 12 de marzo de 2004).

Pero ¿por qué para la Corte Suprema la parte dogmática es superior a la orgánica y por qué, en consecuencia, la limitación constitucional de mandatos puede ser declarada inconstitucional? Toda la respuesta argumentativa se basa curiosamente en una cita que, descontextualizada, se hace de un pasaje de García de Enterría (1994: 97-103). En él, el célebre administrativista español describe las teorías alemanas que más adelante veremos (epígrafe 6) de la superioridad de determinados valores y principios sobre el resto del edificio constitucional, en el que este se fundamentaría. Utilizando expresiones y categorías de honda impronta schmittiana («decisión suprema de la comunidad», «unidad material de sentido»), García de Enterría incluso hace referencia a la teoría de Bachof de que, dados unos valores imbuidos de tal decisión fundamental y ontologizados por encima de cualquier otra disposición, pueden 
existir en la Constitución disposiciones... inconstitucionales. En efecto, si la comunidad política ha decidido que concretos principios sean los que revistan jurídicamente la decisión fundamental originaria de crear y constituir el Estado, tales principios han de presidir todo el andamiaje que se crea, proyectándose sobre él como mandatos con fuerza vinculante y anuladora. Lo cierto es que la cita tampoco se corresponde con la realidad que la Corte Suprema intenta desvelar en esta sentencia. García de Enterría dice expresamente que los valores supremos (que en el caso nicaragüense serían la igualdad, la libertad, el pluralismo político o la unidad centroamericana, consagrados en el timbre de la Constitución) han de prevalecer sobre cualquier «construcción interpretativa y dogmática que concluya con un resultado directa o indirectamente contradictorio con los valores constitucionales» (García de Enterría, 1994: 103). Como puede comprobar fácilmente el lector, el jurista cántabro se refiere específicamente a interpretaciones, no a normas constitucionales per $s e$. La Corte nicaragüense, por el contrario, justo tras citar la frase aquí transcrita de García de Enterría, añade: «De ello se infiere que los Principios Constitucionales que informan nuestra Constitución Política en su Preámbulo y Parte Dogmática, prevalecen sobre el resto de Disposiciones Constitucionales que conforman nuestra Constitución Política» (considerando V, p. 16). Es decir, no sobre las interpretaciones que la propia Corte, en su calidad de supremo intérprete de la Norma Fundamental pudiera hacer, sino sobre partes integrantes de la propia Constitución. Antinomias constitucionales, se aduce, que habrán siempre de ser solventadas a través de la inaplicabilidad y la declaración de inconstitucionalidad de las previsiones constitucionales contrarias a los valores y principios fundamentales y, por lo que se ve, antagónicos.

Sin entrar siquiera a analizar fundamentos externos que puedan rebatir tales posiciones, el yerro en la argumentación interna, basada en la manipulación de una cita doctrinal, parece evidente. Además, acto seguido, la Corte dice que, aunque el constituyente pueda establecer excepciones al principio de igualdad $y$, por ende, reconocer determinadas discriminaciones, estas han de basarse en criterios de justificación objetiva y razonable (considerando VI, p. 17, y considerando VII in toto). La limitación constitucional de mandatos, prosigue, no sería una discriminación ni razonable ni objetiva, por cuanto solo se impone a los cargos electos de presidente y vicepresidente de la República y de alcaldes y vicealcaldes, pero no al resto de los representantes elegidos democráticamente por el pueblo nicaragüense. Olvidando que no corresponde a la Corte la tarea asignada al constituyente de determinar qué excepciones constitucionales se fijan a cualquier precepto constitucional, la Corte asume el rol de intérprete de la voz constituyente obviando que la mejor manera de escucharla es leer lo que en su día, y en teoría, expresaría taxativa y meridianamente en el propio texto constitucional. 
No obstante, intenta fortalecer su posición alegando que la Ley n. ${ }^{\circ} 192$, de 1995, de reforma constitucional, y que es, recordemos, la que incorpora en el texto la limitación de mandatos, no es expresión del poder constituyente, sino del "constituyente derivado», que identifica con el poder de reforma. Por tanto, en su argumentación, no parecería razonable que un constituyente derivado limitara la decisión del constituyente originario.

Empero, cabe recordar que tanto la reforma constitucional de 1995 como la Constitución de 1987 no fueron en ningún momento refrendadas por el pueblo nicaragüense, sometiéndose a procedimientos de aprobación simplemente parlamentarios y sin la legitimidad directa del constituyente. De ahí que aducir una especie de prevalencia de unas normas sobre otras, debido a su supuesta legitimidad de origen, no parece sensato cuando se comprueban los parámetros democráticos usados, y más habida cuenta de las argumentaciones ulteriores que la propia Corte desarrolla.

Por último, la Sala Constitucional (considerando VIII, p. 22) justifica también su resolución de la aparente antinomia a favor de los recurrentes en que la limitación de mandatos, aun constitucionalmente establecida, coarta la libertad del pueblo nicaragüense, que, en uso de su soberanía, decide en las elecciones periódicas que al efecto se celebran quiénes han de ser sus representantes y por cuánto tiempo han de ejercer el mandato. Siendo sustancialmente cierta la afirmación, debe objetarse a la Sala Constitucional nicaragüense que esa decisión soberana sobre quiénes han de ser sus representantes cualquier pueblo la adopta mediante elecciones libres. Pero la decisión sobre por cuánto tiempo han de ejercer el mandato cualquier pueblo la decide en el momento de elaboración del texto constitucional y no cada vez que ejerce su derecho al voto. Por tanto, solo realizando una modificación formal de la Constitución, a través del procedimiento de reforma, podría modificarse tal decisión.

La sentencia, siguiendo los razonamientos aquí expuestos, y pródiga en la cita de autores españoles (Pérez Tremps, Hernández Gil, Aguiar de Luque, López Guerra, García Morillo o el propio García de Enterría), declara finalmente, y como era de esperar, la inaplicabilidad del artículo constitucional que prevé la limitación de mandatos, permitiendo la posibilidad de reelección para la Jefatura del Estado al presidente Daniel Ortega, como así ocurrió tanto en 2011 como, posteriormente, en 2016 (González Marrero, 2012: 137-176).

\section{HONDURAS 2015: LA REELECCIÓN COMO PROBLEMA CENTRAL DE LA CONSTITUCIÓN}

El caso hondureño, sustanciado en 2015 mediante la sentencia de 22 de abril de 2015 (RI 0243-2015), es muy similar al nicaragüense en cuanto a los 
resultados, no así en lo referente a la cuestión de fondo que se analiza, dadas las peculiaridades del sistema constitucional de Honduras. La sentencia, pródiga en extensión pero un tanto parca en argumentación y fundamentación, termina declarando inaplicables el art. 239 de la Constitución, que establece la pérdida de ciudadanía a quienes «inciten, promueven o apoyen el continuismo o la reelección del Presidente de la República», y el art. 42.5, que prohíbe taxativamente la propia reelección mediante una cláusula pétrea o de intangibilidad. En efecto, y aquí es donde reside una de las principales peculiaridades del sistema hondureño (pero no la única, como veremos), el art. 239 impone una pena de inhabilitación de diez años para todos aquellos que quebranten la prohibición o, ¡cuidado!, propongan su reforma. Asimismo, la intangibilidad de la prohibición constitucional se reitera y refuerza en el art. 374, donde se especifica que en ningún caso la reforma de la Constitución podrá afectar a la forma de gobierno y, entre otras cuestiones, a la «prohibición para ser nuevamente Presidente de la República».

Más allá de los excesos punitivos, que comentaremos en las páginas siguientes, vale la pena traer a colación la sentencia de la Corte Suprema de Justicia hondureña, de 26 de marzo de 2008, que declaró inconstitucional una reforma de la Constitución habida en 2003 y con la que se eliminaba la prohibición de que el presidente del Congreso se postulara para la Jefatura del Estado. Es decir, la Constitución de 1982 no solo prohíbe la reelección, sino también la elección (causas de inelegibilidad) a determinados cargos, entre los que no figura sin embargo el presidente del Congreso, y esta previsión queda asimismo amparada en la cláusula de intangibilidad que cierra la Carta Magna. La reforma, al intentar modificar esta prohibición y entrar dentro de tal cláusula, es declarada por motivos formales inconstitucional y nula. Pero, y es lo que aquí nos interesa, el Alto Tribunal hondureño lleva a cabo un análisis, antes de dicha conclusión, sobre la posible compatibilidad de las prohibiciones constitucionales ya existentes con los derechos fundamentales de igualdad y participación política a la luz tanto de la Constitución in toto como de los tratados internacionales suscritos por el Estado hondureño. En la búsqueda de una posible antinomia al respecto, y movida por los argumentos y el petitum de los demandantes, la Corte se reafirma en la pertinencia de las prohibiciones debido a que, en primer lugar, es una decisión del poder constituyente originario que no puede someterse, por ende, a un control jurisdiccional ex post (considerandos 23, 24, 25 y 26), y en segundo lugar, a que la determinación de incompatibilidades, inelegibilidades o prohibiciones responde a otros valores e intereses superiores como la «perpetuación del Estado y la forma republicana», no atentando en ningún momento contra los derechos fundamentales que la misma Constitución establece por cuanto responden tales limitaciones a un fin legítimo y de igual valor jurídico (considerandos 21 y 22). 
De este modo, la sentencia viene a reconocer la supremacía del poder constituyente sobre el poder de reforma a la hora de determinar el contenido de la Constitución, incluyendo la posibilidad de que el primero imponga al segundo una cláusula pétrea o de intangibilidad. El pueblo, defiende la sentencia, en uso de su soberanía, es el que originariamente "crea» el Estado mediante el pacto político que deviene en juridicidad constitucional, y dicha voluntad no puede ser modificada ni siquiera por mayorías cualificadas del poder constituido (Congreso Nacional) que, en el uso de su poder de reforma constitucional, intenten subvertir los límites que el titular de la soberanía en su día les estableció. Imposiciones que, por otra parte, al buscar la persecución de un interés legítimo, como pueda ser la continuidad de la República y del pluralismo político, en el temor de un continuismo autoritario nada extraño en la región, son perfectamente adecuadas y no pueden ser declaradas inconstitucionales ni por su propia naturaleza y fuerza constituyente/constitucional ni por ningún menoscabo de los derechos fundamentales interpretados extensivamente ni siquiera, como la propia Corte aquí indica, a la luz de los tratados y convenios internacionales en la materia. Estos argumentos, además, serían reiterados y reafirmados posteriormente en la sentencia de la Corte $\mathrm{Su}$ prema de 15 de noviembre de 2008.

Aunque no es nuestra labor la de entrar a analizar la realidad fáctica del país, se hace no obstante necesario mencionar siquiera el golpe de Estado que, un año después de estas dos sentencias, en 2009, se perpetró contra el entonces presidente de la República, Manuel Zelaya (Treminio Sánchez, 2016: 242-247). El presidente y su partido, conscientes de la intangibilidad de la prohibición de reelección constitucional y de las trabas que la propia Constitución establecía para su modificación en otros aspectos, llevaron a cabo una campaña para establecer en las nuevas elecciones una «cuarta urna» con la que consultar al pueblo hondureño si quería convocar una asamblea constituyente con el objetivo de cambiar la Constitución. Sin embargo, los tribunales, la oposición (el Partido Nacional) y el Ejército entendieron esta iniciativa como ilegítima e inconstitucional, pues alegaron que se trataba de una estratagema de Zelaya para eliminar la prohibición de reelección y, a través de un golpe de Estado, expulsaron del poder al presidente. Curiosamente será el Partido Nacional, principal denunciante de la maniobra presuntamente reeleccionista de Zelaya y máximo beneficiario del golpe, el que en 2015 promueva el recurso contra la prohibición constitucional de reelección resuelto por la sentencia que ahora abordamos y que, en ese momento de interposición del recurso, impedía que el presidente Juan Orlando Hernández, del mismo Partido Nacional, pudiera optar a la reelección.

Así las cosas, en abril de 2015, y ante las próximas elecciones presidenciales de 2017, un grupo de diputados del Congreso Nacional y el expresidente 
Rafael Leonardo Callejas Romero interponen un recurso de inconstitucionalidad tanto contra los artículos que recogen la ya vista prohibición de reelección presidencial como los que persiguen y penan cualquier debate que la cuestione; impugnación que se hace extensiva a las normas penales que desarrollan las previsiones constitucionales.

De acuerdo con estas, en Honduras constituye delito la defensa o la mera promoción de la posibilidad de reelección, prohibiéndose incluso opinar sobre el ejercicio de este "derecho» bajo penas draconianas: de seis a diez años de cárcel. Previsión a todas luces, como se puede comprobar, desproporcional en cuanto a la defensa de la previsión constitucional, donde no se especifica, además, protección penal alguna.

Aunque en nada tendremos que regresar al derecho penal hondureño, el núcleo de las demandas de los recurrentes que tenemos que destacar se concentra en la posible vulneración de los derechos fundamentales de la propia Constitución por, efectivamente, las previsiones que la misma establece en cuanto a la reelección. Se aduce que la prohibición de esta atenta contra el derecho a la igualdad de los ciudadanos y el derecho a la participación política, así como contra otros derechos humanos y fundamentales amparados en los tratados internacionales ratificados por Honduras en uso de su soberanía. Entre ellos destacaría, además, la Convención Interamericana, que, a juicio de los recurrentes, no posibilitaría la vulneración de tales derechos con base en los arts. 37, 45, 61 y 72 (apdo. 2 de la sentencia). Asimismo, se citan la Declaración Universal de los Derechos Humanos (arts. 2, 7, 10, 18 y 19), el Pacto Internacional de Derechos Civiles y Políticos (arts. 2, 3, 19 y 26) y hasta vagas referencias al derecho natural.

La Corte asume esta teórica antinomia en el interior de la Constitución y la termina resolviendo a favor de los derechos que entiende vulnerados a través de lo que creemos que constituye una tergiversación del planteamiento de Ferrajoli. En efecto, en el considerando $1 .^{\circ}$ se hace referencia explícita a la consabida doctrina del jurista italiano y a su libro Poderes salvajes (Ferrajoli, 2011) para defender la posibilidad de declarar inaplicables previsiones constitucionales por vulneración de los derechos fundamentales, en la medida en que estos, como defiende el florentino, serían indisponibles para los poderes constituidos y aun para las expresiones más enfáticas de la soberanía popular. Ahora bien, al contrario de lo que enseguida infiere de manera infundada la Corte Suprema, de la cita de Ferrajoli no puede desprenderse la defensa por este de la inconstitucionalidad de normas constitucionales que limiten, desde el poder constituyente, el ejercicio de los poderes constituidos (Rivera Portillo, 2017: 78 y ss.). Es más, este es el origen mismo y el objetivo último de toda la concepción constitucionalista, de la que Ferrajoli es un firme defensor y uno de sus más famosos baluartes contemporáneos: el de restringir y dividir 
el poder para evitar su concentración y su extralimitación. La Constitución, en el pensamiento del profesor italiano, se erige en el medio más eficaz de controlar al poder (no solo político, sino también económico y mediático), y para ello el prediseño constituyente de la parte orgánica de toda carta magna se vuelve esencial. Es esta parte, con su sistema de pesos y contrapesos y sus limitaciones más contundentes, la que crea el marco institucional más óptimo para el libre desenvolvimiento de los derechos fundamentales y su disfrute por parte de los ciudadanos. Restricciones como la limitación de mandatos, que se derivan de esta concepción constitucionalista y limitativa del poder político no solo no serían rechazadas en el seno del garantismo, sino, por el contrario, impulsadas. Volveremos a ello más adelante.

Sea como fuere, de esta pretendida interpretación ferrajoliana la Corte deduce los demás presupuestos argumentativos que sustentan el fallo, olvidándose de las sentencias anteriormente dictadas y sucintamente analizadas anteriormente. En los considerandos $3 .^{\circ}, 4 .^{\circ}$ y $5 .^{\circ}$ intenta, en este sentido, reforzar la supuesta antinomia al insistir en que la limitación constitucional de mandatos restringe la capacidad «soberana de participación cívica y política de los asuntos concernientes al Estado" [sic], confundiendo así el ejercicio ordinario y juridificado de la función electiva con el ejercicio extraordinario de la función constituyente. Además, la Corte afirma tal presuposición alegando la vulneración de un «derecho universal de elegir y ser electo", sin atender a la posibilidad de que este pueda ser modulado en la parte orgánica para salvaguardar otros legítimos intereses o valores constitucionales, en la medida, además, en que caben excepciones a las normas generales desde el mismo rango jerárquico. Por si fuera poco, la Corte inserta el derecho en las normas internacionales de ius cogens, equiparando así un supuesto derecho humano a la reelección con las convenciones de La Haya.

Posteriormente, citando incluso al Tribunal Constitucional español, la Alta Corte hondureña redunda en la necesidad de interpretar las leyes conforme a los derechos fundamentales y a principios como el pro homine, confundiendo constantemente el control jurisdiccional de constitucionalidad de las leyes, inferiores en rango a la Constitución, con la supuesta necesidad de proteger esta de sí misma (Rivera Portillo, 2017: 93). Y es que, sencillamente, no pueden aplicarse los mismos criterios interpretativos que se proyectan desde los derechos fundamentales sobre las leyes de desarrollo, los que pretendidamente se intentan elaborar para solucionar antinomias entre disposiciones constitucionales de igual valor jerárquico normativo y de igual legitimidad.

En los considerandos 10 y 11, por su parte, se llega al cénit de la paradoja. La Corte afirma que la limitación de mandatos supone una restricción desproporcional que atenta contra los principios pro homine y al derecho de libertad, denunciando la falta de consideración que, supuestamente, el 
constituyente tuvo hacia ellos. El Alto Tribunal no interpreta aquí la Constitución, sino que directamente sustituye, como vemos, al propio poder constituyente; operación aún más gravosa e impactante, pues alega que actualmente es innecesaria de la limitación de mandatos, después de que [sic] «diez procesos electorales hayan contribuido a fortalecer el ejercicio de los derechos políticos en el sistema democrático [hondureño]». No hace falta acudir a informes internacionales para develar tal impostura, pues recordemos que fue precisamente la problemática de la reelección presidencial la que desencadenó el golpe de Estado contra el presidente Zelaya en 2009.

En el considerando 14 la Corte analiza algo que, a priori, no debiera ser objeto de atención en este estudio, pero que, aun no estando ligado a la limitación de mandatos, es utilizado torticeramente en la sentencia para hacer una deducción inversa. Nos referimos a la restricción de la libertad de expresión que implica el tratamiento draconiano que hace el Código Penal en cuanto a la temática de la reelección, y que ya indicamos (imposición de penas altísimas por la mera formulación de opiniones al respecto). Pues bien, y aunque pueda resultar extraño, el Alto Tribunal termina concluyendo la inaplicabilidad final de la cláusula de reelección por la inconstitucionalidad de tales previsiones penales, obviando que estas no se desprenden de mandato constitucional alguno y que sí pueden ser analizadas bajo el prisma del control jurisdiccional de constitucionalidad de las leyes al amparo, ahora sí, de los derechos fundamentales. En un totum revolutum final, la Corte, aduciendo también la vulneración de la Convención Interamericana y el respeto a la libertad de expresión que esta impone, termina la sentencia y determina el fallo sin haber vuelto a la cuestión principal de la propia ratio decidendi, a saber: la aplicabilidad o no de la limitación constitucional de la reelección presidencial, declarándola finalmente... inaplicable.

En resumen, la Corte contradice su propia jurisprudencia anterior, donde ya había aclarado, como vimos, que las restricciones constitucionales para la elección o reelección respondían a intereses legítimos (preservación de la forma republicana inter alia) y que eran, por ende, aceptables, para declarar inaplicable (trasunto de inconstitucional) el art. 239 de la Constitución, que establece la prohibición de la reelección presidencial; prohibición que, recordemos, estaría sujeta, además, y por si fuera poco, a una cláusula de intangibilidad siguiendo los deseos constituyentes. Y todo ello lo realiza mediante una argumentación endeble, carente de fundamento o, cuando no, directamente paradójica en su dinámica interna, en la que se aducen desde el derecho natural a pretendidas disposiciones de ius cogens, para terminar deduciendo de la inconstitucionalidad (posible y hasta deseable) de unas previsiones penales, la propia inconstitucionalidad de unas disposiciones de la Carta Magna que, ni siquiera, les dan cobertura. Como dicen en su temprano análisis de la 
sentencia Zúñiga Urbina y Cárcamo Tapia, «la Corte Suprema hondureña ha pasado con su decisión todo límite: si un poder constituido ignora su calidad de tal, reformando la norma que lo legitima como poder público, se transforma en definitiva en poder constituyente y, por tanto, en usurpador de la soberanía popular» $(2015: 228)$.

\section{BOLIVIA 2017: EL TRIBUNAL CONSTITUCIONAL CONTRA LA VOLUNTAD DE LOS CIUDADANOS}

El caso de Bolivia reviste especial gravedad porque la sentencia del Tribunal Constitucional que ha permitido que el presidente de la República pueda ser reelecto se produce después de que tuviera lugar un malogrado proceso de reforma constitucional, ad hoc, para eliminar la prohibición de reelección presidencial que, como veremos, fue abortado por el voto negativo a dicha reforma mediante referéndum popular.

Tras la llegada al poder del presidente Evo Morales en 2005, y la convocatoria de una Asamblea Constituyente en 2006, se había producido en el país un proceso de transformación sin igual en su historia, rica en avatares autoritarios y dependencias oligárquicas y extranjeras. La inestabilidad de la constituyente, continuamente boicoteada por la oposición conservadora, hizo que el texto definitivo de 2009 fuera en algunos aspectos esenciales el resultado de un compromiso entre fuerzas políticas contrapuestas (Viciano Pastor y Storini, 2016). Uno de los resultados de aquellas tensiones y transacciones fue, de hecho, el acuerdo de que el presidente no pudiera ser reelegido en más de una ocasión. La nueva Constitución boliviana, aprobada por el pueblo el 25 de enero de 2009, estableció en su art. 168 que el período de mandato del presidente y el vicepresidente del Estado Plurinacional fuera de cinco años, pudiendo ser reelectos por una sola vez, de manera continua. Asimismo, la disposición transitoria primera de la Constitución boliviana establece en su apdo. II: «Los mandatos anteriores a la vigencia de esta Constitución serán tomados en cuenta a los efectos del cómputo de nuevos períodos de funciones».

Sin embargo, y pese a la clara redacción de la disposición transitoria primera, el Tribunal Constitucional Plurinacional (TCP, en adelante) determinó en su Declaración Constitucional Plurinacional n. ${ }^{\circ}$ 0003/2013 la constitucionalidad de la Ley n. ${ }^{\circ} 381$ de Aplicación normativa, por la que la Asamblea Plurinacional hacía una interpretación, sui generis, del texto constitucional para entender que el primer período de mandato del presidente y del vicepresidente, a los efectos de reelección, era el surgido de las primeras elecciones posconstitucionales, considerando como no computable el mandato 2006-2009, anterior a la vigencia de la nueva Constitución. En consecuencia, 
presidente y vicepresidente pudieron ser nuevamente postulados en las elecciones de 2014.

Pues bien, ante la cercanía del final del segundo mandato posconstitucional del presidente Morales, y dado que ya no cabía interpretación alguna que permitiera una nueva postulación, la Coordinadora Nacional por el Cambio, que agrupa a diversas organizaciones sociales afines al actual Gobierno boliviano, propuso reformar la Constitución con el fin de que pudiera volverse a presentar el presidente Morales.

La propuesta de reforma prosperó en una Asamblea Legislativa Plurinacional dominada por mayoría de dos tercios, tanto en la Cámara de Diputados como en el Senado, por el oficialista Movimiento al Socialismo (MAS). No obstante, sometida la reforma constitucional a referéndum popular el 21 de febrero de 2016, tal como obliga el art. 411 de la Constitución boliviana, la modificación fue rechazada por el voto popular en un ajustado resultado ${ }^{3}$.

Cerrada, pues, la vía de la reforma constitucional para poder repostular a Evo Morales a la presidencia del Estado Plurinacional, un grupo de diputados y diputadas de la Asamblea Legislativa Plurinacional, pertenecientes a la mayoría gubernamental, interpusieron ante el Tribunal Constitucional Plurinacional una acción de inconstitucionalidad abstracta solicitando la inaplicabilidad de los arts. 156, 168, 285.II y 288 de la Constitución boliviana, que limitan la reelección de autoridades ejecutivas nacionales, ejecutivas y legislativas departamentales y municipales a una sola vez de manera continua, por entender que contradecían los arts. 26 y 28 de la misma Constitución, que establecen la posibilidad de que todos los ciudadanos bolivianos puedan ser candidatos y postularse a elecciones limpias y justas. Asimismo, entendían que contradecían los arts. 1.1, 23, 24 y 29 de la Convención Interamericana de Derechos Humanos, dado que la Constitución boliviana en su art. 256.1 establece que los tratados y convenios internacionales sobre derechos humanos que declaren derechos más favorables a los contenidos en la Constitución se aplicarán de manera preferente a esta (Noguera Fernández, 2010: 121-142). También se alegaba por los accionantes que los arts. 13.IV y 256 de la Constitución establecen que los derechos y deberes consagrados por la misma se interpretarán de conformidad con los tratados internacionales de derechos humanos ratificados por Bolivia, cuando estos prevean normas más favorables; y que el art. 410.II del texto fundamental establece que los tratados

3 De acuerdo con el Órgano Electoral Plurinacional, los resultados fueron los siguientes: a favor de la reforma y de la posibilidad de reelección, un 48,7 \% de los votantes; en contra, un $51,3 \%$. 
y convenios internacionales sobre derechos humanos integran el bloque de constitucionalidad.

Para resolver la acción de inconstitucionalidad de carácter abstracto el TCP dictó la sentencia constitucional 0084/2017, de 28 de noviembre de 2017, en la que estimó la acción declarando inaplicables los arts. 156, 168, 285.II y 288 de la Constitución boliviana y permitiendo, con ello, la reelección.

Debe reseñarse que los accionantes solicitaban en primer lugar la declaración de la inconstitucionalidad de los preceptos de la Ley de Régimen Electoral y, en segundo lugar, la inaplicación de los artículos constitucionales citados, dado que hubiera sido más complicado plantear directamente la inaplicación de preceptos constitucionales por colisión con otras previsiones constitucionales y convencionales, ya que el art. 72 de la Constitución señala que las acciones de inconstitucionalidad podrán presentarse contra cualquier norma jurídica incluida en una ley, decreto o resolución de cualquier tipo no judicial que sea contraria a la Constitución, y el art. 73 indica que las acciones de inconstitucionalidad de carácter abstracto procederán contra leyes, estatutos autonómicos, cartas orgánicas, decretos, ordenanzas y todo género de resoluciones no judiciales.

Obviamente, la Constitución no prevé la posibilidad de acciones de inconstitucionalidad de carácter abstracto contra preceptos constitucionales (Rivera Santivañez, 2018: 44 y 45), a pesar de lo cual el TCP, en el punto III.4 de los fundamentos jurídicos de la sentencia, se autoatribuye la facultad de realizar el control de constitucionalidad de preceptos constitucionales, pues, según el Tribunal, el art. 196 de la Constitución Política del Estado atribuye la función de control de constitucionalidad al Tribunal,

labor que no solo implica el control de las normas del ordenamiento infra constitucional y su compatibilidad con la Constitución, sino que además, debe velar por la armonía y coherencia de las normas que lo conforman, por lo que a partir de la disposición constitucional citada, es posible asumir la existencia de una «facultad extendida", para que este Tribunal realice el control de constitucionalidad de las propias normas constitucionales, cuidando que en todo su entramado no existan normas disonantes con los valores supremos, principios fundamentales, derechos y garantías que consagra el orden constitucional, garantizando armonía y coherencia en sus términos.

Dado que la sentencia es bastante caótica en lo referente a la ordenación de la ratio decidendi y peca de saltar desordenadamente de unas consideraciones a otras sin demasiada lógica, intentaremos ordenar el razonamiento del Tribunal. 
Fundamentalmente, el TCP estructura su decisión alrededor de dos líneas argumentales: por un lado, la posibilidad de normas constitucionales inconstitucionales, y por otro, la aplicación preferente de las normas más favorables de los tratados internacionales de derechos humanos sobre los preceptos constitucionales en aplicación del control de convencionalidad.

Respecto al primer eje discursivo, el Tribunal, apoyándose en citas doctrinales de Bachof y de Yolanda Gómez, así como en jurisprudencia del Tribunal Constitucional alemán, defiende que es posible la existencia de normas constitucionales inconstitucionales (véase el epígrafe 6). Argumenta su posición diferenciando entre normas-principios y normas-reglas, y atribuyendo a las primeras una posición preferente dentro de la propia Constitución. Al margen, el TCP utiliza de forma tergiversada la jurisprudencia alemana, pues cita una sentencia del «Tribunal Constitucional alemán» de 1949 (el Tribunal Constitucional alemán se constituyó en septiembre de 1951) que, además de existir, resolvería un caso de contradicción de la Constitución de Baviera con la Ley Fundamental de Bonn, es decir, una contradicción entre una constitución de un Estado federado y la constitución federal.

El otro argumento que el TCP sostiene en su sentencia, a saber, el de la aplicación preferente de los tratados internacionales sobre derechos humanos más favorables respecto a las previsiones constitucionales, es curiosamente el único que parece determinar finalmente el fallo del Tribunal, que se olvida en sus últimos razonamientos de la presunta inconstitucionalidad de los preceptos constitucionales que prevén la limitación de mandatos. Y aquí, nuevamente, el ejercicio de exégesis es abiertamente criticable y de inexistente fundamentación. Aunque, como hemos señalado, la Constitución boliviana recoja esa previsión en favor de los derechos humanos, que se ven amparados así en sus formulaciones más progresistas por la integración directa y ex constitutione del derecho internacional en el ordenamiento nacional, no cabe una interpretación pretoriana en sede local de la Convención Interamericana que sirva para soslayar la Carta Magna nacional sin apoyarse, siquiera mínimamente, en la posible jurisprudencia de la Corte Interamericana. Ni la Convención dice que haya un derecho «humano» a la reelección, como afirma el TCP, ni existe sentencia alguna de la Corte de San José que así lo establezca. Como veremos en el apartado 6.1, lo que hace el TCP, siguiendo a alguno de sus homólogos centroamericanos, es una interpretación torticera y muy peligrosa del control de convencionalidad con el único objetivo, manifiesto, de evadir con pretensiones de juridicidad la propia norma fundamental que le da carta de existencia al Tribunal y a las funciones que tiene encomendadas.

Por último, hay que destacar lo inconsistente del razonamiento tangencial que sobrevuela toda la sentencia, el de la deliberada existencia de una antinomia entre normas constitucionales. Es más, el TCP fundamenta su 
argumentación en otra sentencia suya anterior en la que sí pretendía resolver una posible y auténtica antinomia (apdo. III.4, antinomia entre arts. 172.15 y 214 de la Constitución boliviana) para, con ello, intentar trasladar esa correcta utilización de un mecanismo de aplicación de la Constitución a un fraude interpretativo. $\mathrm{Y}$ es que en este caso no estaríamos ante normas contradictorias, sino ante una norma de alcance general y una de carácter especial, es decir, una excepción prevista con igual rango constitucional a una regla de alcance general de idéntico valor jurídico. Recalcamos, y como veremos en el siguiente epígrafe, que la mera posibilidad de sostener que existen, a día de hoy y en el marco de constituciones democráticas, normas de una Carta Magna que son inconstitucionales es, simple y llanamente, inadmisible.

\section{VI. ¿NNORMAS CONSTITUCIONALES INCONSTITUCIONALES?}

A pesar de la novedad de las sentencias analizadas, hubo un tiempo en que no fue extraño a la dogmática jurídica el debate en torno a la posibilidad de que existieran normas constitucionales que fueran inconstitucionales. En 1951 el profesor alemán Otto Bachof impartiría en la Universidad de Heidelberg una conferencia inaugural que, tras su publicación como libro, se convertiría con el tiempo en la obra de referencia sobre la materia (Bachof, 2010). $\mathrm{Y}$ aunque no es citado en ningún momento por las Cortes Constitucionales de Nicaragua, Costa Rica y Honduras y sí por la de Bolivia (FJ III.4), los razonamientos del jurista de Tubinga son los que, de un modo u otro, subyacen a las respectivas elaboraciones jurisprudenciales, deudoras de la concepción que Bachof tenía de la Constitución y que en España fueron en su momento determinantes en algunos autores, como la también citada por el TCP boliviano, Yolanda Gómez (Gómez Sánchez y Mellado Prado, 1986: 175-194). Para Bachof la Constitución sería, como pone de manifiesto en su discurso, un «todo» complejo que no se reduciría a la norma fundamental escrita, sino que estaría abierto a las extensiones que, materialmente, fueran anejas a la propia dinámica de la democracia constitucional, la cual, para Bachof, encontraría sus fundamentos también más allá de la Constitución en sentido formal. Las concepciones de la dignidad, los derechos humanos o los valores inherentes a la democracia y a la unidad federal del Estado (alemán) serían superiores al orden constitucional escrito en la medida en que, de acuerdo con una concepción iusnaturalista, son elementos en sí mismos anteriores al ejercicio del propio poder constituyente. Bachof habla en este sentido de "derecho constitucional metapositivo" para referirse a ese conjunto de valores, principios y derechos que son anteriores a la voluntad democrática del pueblo erigido en constituyente y, por tanto, anteriores al surgimiento mismo de la Constitución formal. 
El problema de su inconcreción y del excesivo iusnaturalismo escolástico que rezuma tal afirmación es atenuado por Bachof a través de la consideración del reconocimiento positivizado de tales imperativos. Cuando la Constitución reconoce determinado sistema de valores no constituye ex nibilo este, sino que se limita a la constatación por positivización, es decir, a la traslación a norma escrita de su existencia preconstitucional (Bachof, 2010: 65). Las cláusulas de apertura que contienen muchas cartas magnas, incluidas las latinoamericanas, en las que se hace referencia explícita al reconocimiento de los derechos humanos o de conceptos tan amplios como la justicia o la libertad, serían las puertas positivizadoras en su reconocimiento de la existencia de valores superiores a la Constitución misma, por ser anteriores a ella y aun así bendecidos por su decisión. De este modo, se estaría incluso poniendo límites a la acción del poder constituyente, por cuanto nunca podría conculcar esos principios supra o metapositivos que le son anteriores y «cuyo respeto es condición de validez de los mismos preceptos de la Constitución escrita» (ibid:: 16-17 y 54; Stern, 1987: 320-322). Al mismo tiempo Bachof parece dar cabida a ciertas concepciones schmittianas con la afirmación del supuesto de que, aun en el interior de la Constitución misma, existen diferentes jerarquías debido a la intensidad con que la decisión fundamental se manifiesta. Siguiendo la tesis del polémico jurista, se podría así distinguir entre Constitución strictu sensu, en la que estaría contenida al más alto nivel la decisión del poder constituyente, y la ley constitucional, extensión subordinada de aquella (Schmitt, 2011). Por supuesto, Bachof no aplica tal concepción a veleidades totalitarias o a la necesidad de un Jefe de Estado que garantice la unidad, sino a la determinación de concretas previsiones constitucionales, referentes a los derechos y a valores esenciales del orden democrático, como superiores al resto.

Hemos de tener en cuenta, y no es baladí recordarlo, que el contexto en el que se desenvuelve su teoría es el de la Alemania de posguerra, inundada aún del temor hacia el totalitarismo y sus posibilidades de retorno, e imbuida, en consecuencia, de una visión de «democracia militante» que es extraña para los sistemas constitucionales de su entorno. Es más, durante la elaboración de dicha teoría existía en la propia Alemania un debate intenso sobre la posible subordinación de la Ley Fundamental de Bonn no ya a categorías indefinidas de derechos humanos o de valores democráticos, sino al mismísimo derecho de ocupación militar que, aún por entonces, se estaba aplicando por parte de las potencias aliadas (Bachof, 2010: 31-32). Al margen de ello, la necesidad de dotar de instrumentos fuertes de autodefensa a la democracia constitucional recién inaugurada, con el recuerdo funesto de la historia reciente, alentaba interpretaciones extensivas de la proyección de los derechos y, cómo no, la recepción positiva de las cláusulas de intangibilidad que la Ley Fundamental imponía al propio poder de reforma constitucional. La dignidad de la persona 
y la forma democrática y federal de Alemania eran y son previsiones pétreas que resisten la acción de la reforma y a las que, aplicando cierta lógica también un tanto schmittiana, Bachof parece darles mayor posición jerárquica. El constituyente originario habría así decidido dotar de inmutabilidad plena (a no ser que él mismo fuese de nuevo el protagonista) a determinados aspectos de la Constitución que, por su propia naturaleza inmodificable, serían superiores al resto de disposiciones constitucionales, abriéndose con ello la veda a poder declarar inválidas, por contradicción, estas.

Compartimos con Bachof, como no podría ser de otro modo, que una vez asumida la existencia de cláusulas pétreas o de intangibilidad, estas, de tener una legitimación democrática directa, serían inmunes a la reforma constitucional ejercida por los poderes constituidos (ibid.: 73-76). Sin embargo, el jurista alemán parece extender por analogía tal consideración a la posible existencia de jerarquías internas dentro de la Constitución, más allá de la reforma de esta, es decir, dentro del propio texto originario creado por el constituyente. Nos parece un salto no solo cualitativo y poco argumentado, sino, sobre todo, erróneo, en la medida en que se tiende a confundir al poder constituyente originario con el poder, derivado, de reforma; confusión doctrinal nada infrecuente ya denunciada, con magisterial brillantez, por el profesor De Vega (2011).

El principal problema reside en la reafirmación, con todo, que hace $\mathrm{Ba}-$ chof de sus formulaciones iniciales sobre la pertinencia de que puedan existir normas constitucionales inconstitucionales que respondan a jerarquías internas de la Norma Fundamental, ya sea por explícitas decisiones del poder constituyente al crear cláusulas pétreas, ya sea por la apertura de la Constitución misma al derecho constitucional metapositivo y su reconocimiento jurídico. La infracción de este invalidaría las disposiciones constitucionales causantes de la conculcación (2010: 83 y ss.), aun cuando, y aquí Bachof realiza otro salto cualitativo, ni siquiera existiera una cláusula de reconocimiento, de positivización, de dicho derecho metapositivo. De este modo la concepción del derecho natural hace aparición con inusitada fuerza, para sostener, siguiendo a autores como Von Hippel, que existen "principios constitutivos subyacentes al texto constitucional» que, aun no estando reconocidos en este, le dan carta de existencia por su necesidad misma (ibid.: 88-90). Bachof no aclara cómo y con qué criterios pueden determinarse dichos principios, parámetros ellos mismos de la constitucionalidad de la propia Constitución, pero sí se atreve a atribuir a la jurisdicción constitucional tal función (ibid.: 93-112). La ampliación del margen de discrecionalidad de los tribunales constitucionales, habilitados ahora para declarar inválidas partes de la Constitución a la que en teoría deben defender, sería cuanto menos considerable y, con total seguridad, contraria al espíritu kelseniano que les dio vida. 
Ahora bien, no es de extrañar que, en un contexto constitucional de profusión del neoconstitucionalismo y el garantismo en América Latina, donde las Cortes Constitucionales se erigen en verdaderos baluartes de la determinación del orden constitucional y su alcance, tesis como las expuestas de Bachof hayan tenido cierto predicamento, pues legitiman la extensión de las funciones del juez constitucional y esa es, precisamente, una de las claves de tales teorías (Zúñiga Urbina y Cárcamo Tapia, 2015). La teoría de la sustitución constitucional en Colombia que se ha desplegado ya en múltiples sentencias (Corte Constitucional de la República de Colombia, 2010, Rol C-141/10, c. 6.3.7, inter alia) da buena cuenta de esta realidad (Tovar Uricoechea, 2017), pues aunque a veces no se cite explícitamente a Bachof, los argumentos utilizados por la Corte Constitucional son similares al asumir no solo la existencia de jerarquías internas en la Carta Magna, sino su propia competencia para determinarlas e interpretarlas.

Esta es, en el fondo, la tesis también asumida por las Cortes de Nicaragua, Honduras, Bolivia y, en menor medida, Costa Rica, al aceptar que puedan existir normas constitucionales inválidas, inaplicables o inconstitucionales (sea cual sea la calificación), por contravenir otras de mayor jerarquía, estén o no explícitamente positivizadas en la propia Constitución. La aceptación de la posibilidad de antinomias constitucionales es el primer paso en la aceptación final de su resolución a favor de pretendidas expansiones de derechos positivizados o de la invención, lisa y llana, de nuevos derechos. Curioso es, en este sentido, que en la única constitución de las tres que sí tiene cláusulas pétreas que podrían justificar, al menos, un control de constitucionalidad de las reformas, como es el caso de la hondureña, la Corte las obvie y, directamente, las declare inaplicables por contravenir otros preceptos constitucionales (i!). Si asumiendo los postulados de Bachof pudiera haber una parte de la Constitución hondureña superior al resto, esa sería precisamente la de las cláusulas pétreas susceptibles de resistir a las propias reformas constitucionales.

En este sentido, llama aquí la atención la referencia explícita que se hace de Ferrajoli y sus tesis en algunas de las sentencias analizadas, especialmente en la hondureña. Intentar sustentar la argumentación en los postulados de Bachof y en el único argumento de jerarquías internas es difícil dialécticamente cuando, como vemos, existen cláusulas pétreas o el objeto de lo analizado, la reelección, no es parte inherente de todo sistema democrático. Por ello, se tiende en las cuatro sentencias a dar una mayor jerarquía normativa a los derechos fundamentales sobre las regulaciones de la parte orgánica de la Constitución, primando los primeros sobre las limitaciones estructurales que esta última establece. Y ello se hace mediante la petrificación material o informal de los derechos fundamentales y de una determinada interpretación extensiva, en virtud del núcleo indisponible o «el coto vedado» de los derechos. Si 
el constituyente, ya sea el hondureño o el boliviano, no ha establecido como intangibles las previsiones en materia de derechos fundamentales, la Corte constitucional así las considera en tanto pertenecen, para ella, a ese conjunto no decidible por parte de los poderes constituidos al ser, el conjunto mismo, inmanente a la concepción holística de la democracia. Las Cortes encuentran una posible argumentación, de este modo, en la mixtura entre las tesis de Bachof y las del garantismo de Ferrajoli, para, apoyándose en la potenciación de sus funciones que ampara el neoconstitucionalismo, declarar inaplicables las prohibiciones constitucionales de la reelección presidencial.

$\mathrm{Al}$ margen de las contradicciones internas, creemos inapropiada tal operación argumentativa por dos motivos, principalmente. En primer lugar, el núcleo indisponible del que hablan Ferrajoli o Valdés se predica de aquellos prerrequisitos sin los cuales la democracia, desde el punto de vista valorativo, no puede darse, y entre ellos no figura la reelección indefinida del presidente. Los derechos fundamentales, como el de participación política o el de igualdad, no son absolutos, y eso lo reconocen y lo alientan los propios autores citados, ya que pueden ser especificados, con justa causa y persiguiendo siempre un interés legítimo, en la propia Constitución. Cuando, por ejemplo, se exige que sean juristas de reconocido prestigio con más de quince años de experiencia los que puedan optar a magistrados del Tribunal Constitucional, o cuando se restringe la participación política a los menores de dieciocho años, no se está atacando frontalmente el derecho fundamental a la igualdad. La delimitación de los poderes del Estado y la restricción de su ejercicio pueden responder a intereses legítimos perseguidos por la propia Constitución en la salvaguarda de los valores y principios que enarbola. Y sin duda, como reconocían las primeras sentencias hondureñas, la prohibición de la reelección puede ampararse en la necesidad de proteger la forma republicana de gobierno y el principio democrático, dado el historial, nada lejano, de tiranías, Gobiernos autoritarios y caudillismos que ha sufrido y sufre Latinoamérica. La antinomia aquí es falsa, pues siempre habrá concreciones en la parte orgánica de la Constitución, que, por la necesidad misma de su existencia y la naturaleza de la ordenación de los poderes del Estado, «choquen» en el plano teórico con las formulaciones abstractas y absolutas de derechos como el de igualdad o el de participación. En el plano teórico, decimos, pues en el concreto opera sin ambages el principio de especialidad, de igual legitimación en su origen por estar fundamentado en la decisión constituyente. Pero es que, además, tomando como propios los argumentos del garantismo, la prohibición constitucional de la reelección, en sus distintas formas, puede ser una forma más de garantizar no solo la pervivencia republicana y el Estado de derecho fuera de todo personalismo, sino también el propio derecho de participación política, en su conjunto, al establecerse obligatoriamente la alternancia en la más alta 
magistratura del Estado. El objeto del garantismo no es otro, en definitiva, que el de encontrar los medios e instrumentos jurídicos óptimos para la salvaguarda de los derechos fundamentales y su recto cumplimiento, haciendo hincapié tanto en las garantías jurisdiccionales y normativas de estos como en la articulación de los poderes que han de darles cobertura; siguiendo aquí, en efecto, la larga tradición del liberalismo político y del control constitucional del poder.

En segundo lugar, creemos equivocada la interpretación que las Cortes llevan a cabo de la traslación jurídica de la voluntad constituyente. Si esta, ilimitada por su naturaleza política y no jurídica, fundadora ella misma del orden constitucional y legitimadora primera de los poderes del Estado que constituye, no ha decidido explícitamente la superioridad o inferioridad jerárquica de determinados valores o previsiones constitucionales, no cabe deducirlo de débiles ejercicios hermenéuticos que amplían hasta límites insospechados la función de la justicia constitucional. Solo sería posible desde una lógica antipositivista la justificación de tal ampliación sobre la base, ciertamente polémica, de la asunción de postulados claramente iusnaturales, es decir, del reconocimiento de un derecho superior a la Constitución positiva por la potencialidad de sus implicaciones morales. Sin embargo, y como pronto advirtió Kelsen (1974), ello desvirtuaría de tal modo la naturaleza de la justicia constitucional que dejaría de adjetivarse así para pasar a ser, al final, una especie de eforado espartano que ve en los auspicios y en el vuelo de las águilas las esencias de la democracia. La pérdida de referencia en las Cortes constitucionales del texto normativo que les da soporte y carta de existencia, y la vinculación de sus decisiones a concepciones morales, no solo haría de la justicia constitucional un oxímoron, sino también un mecanismo elitista y profundamente antidemocrático de gran alcance y extraordinaria gravedad.

\section{EL PRETENDIDO «DERECHO HUMANO» A LA REELECCIÓN O LA UTILIZACIÓN TORTICERA DEL CONTROL DE CONVENCIONALIDAD}

Lo más preocupante de las sentencias que estamos estudiando quizá no resida, sin embargo, en los principales equívocos de sus argumentaciones, sino en el producto final de estas, a saber: la consideración de la reelección como parte indeleble de los derechos fundamentales a la igualdad y a la participación política cuando no, directamente, como derecho humano en sí mismo considerado.

Las referencias continuas a la Declaración Universal de los Derechos Humanos o al Pacto Internacional de Derechos Civiles y Políticos obvian que en ninguno de estos documentos se hace explícita referencia a un derecho a la reelección, y que, por el contrario, sí contienen previsiones de salvaguarda en 
la configuración institucional de los respectivos Estados firmantes. Asimismo, y dado el contexto latinoamericano en el que se dan las cuatro sentencias y la imbricación de sus sistemas constitucionales en el marco de la Convención Interamericana de Derechos Humanos, las referencias a esta son múltiples y continuas. Las Cortes intentan con ello vincular los rudos arados de sus interpretaciones constitucionales con la apertura, ambigüedad e indeterminación de la Convención para, de este modo, conseguir que su eficacia directa baje desde las alturas y reafirme las posiciones que hemos criticado en el epígrafe anterior. Y sin embargo, a pesar de esta constante referencia a la Convención (art. 23) y a la Corte Interamericana de Derechos Humanos, no conseguimos ver ninguna interpretación de esta, ninguna decisión, que sea favorable a entender el derecho de participación política o el de igualdad como baluartes de la reelección sine die. Ninguna sentencia, repetimos.

El dictum más prolijo en sus referencias al control de convencionalidad, hasta el punto de que hace de este el verdadero mecanismo de interpretación final, es el boliviano. Como ya hemos comentado, la Constitución de 2009 incorpora una cláusula de apertura en su art. 256.I por la que cede su propia jerarquía normativa suprema a favor de los tratados y convenios internacionales en materia de derechos humanos, al permitir que estos se apliquen de manera preferente si declaran derechos más favorables a los contenidos en la propia Constitución. Un caso único, diferente a los de Honduras o Nicaragua, en el que el constituyente ha decidido explícitamente positivizar lo que Bachof llamaba derecho metapositivo, y que en el contexto de las democracias constitucionales contemporáneas no puede ser más que la interpretación que los tribunales internacionales hagan de los tratados de derechos humanos, es decir, de un derecho positivo strictu sensu. Cuando dicha interpretación sea más favorable que el alcance de los propios derechos contenidos en la Constitución, estos cederán su preeminencia a aquella. De ahí que el Tribunal Constitucional Plurinacional acuda presto al control de convencionalidad, es decir, a la obligación que tienen todos los jueces y poderes establecidos de aplicar directamente la Convención e inaplicar el derecho interno contrario a esta, y que fue reconocido en Bolivia en sentencias como la 0110/2010-R, de 10 de mayo. Además, el Tribunal recuerda que ni siquiera la Constitución puede resistir el control de convencionalidad (considerando III.1), acudiendo sin citarla a la doctrina asentada, inter alia, en Gelman vs. Uruguay (Sentencia de 24 de febrero de 2011).

Ahora bien, ¿existe una interpretación extensiva de la Corte Interamericana sobre el derecho de participación política que anule la prohibición constitucional de la reelección? La respuesta ha de ser, como ya hemos anticipado, rotundamente negativa. En la sentencia Castañeda Gutman vs. México, de 6 de agosto de 2008, profusamente citada, la Corte Interamericana estableció 
la imposibilidad, por ser contraria al art. 23 de la Convención, de discriminar sin justificación legítima a los candidatos en un proceso electoral, que deberán en todo caso participar en pie de igualdad, jurisprudencia que ha sido reiterada en casos como López Mendoza vs. Venezuela, de 1 de septiembre de 2011, o Argüelles y otros vs. Argentina, de 20 de noviembre de 2014, y que también son citados in extenso. Pero en ninguno de ellos se afirma por parte de la Corte que la prohibición constitucional de reelección atente contra el derecho de participación política o de igualdad, puesto que se entiende que estos han de operar dentro de las limitaciones orgánicas que las respectivas constituciones establecen, limitaciones que han de estar, evidentemente, justificadas y ser legítimas. La propia Corte, en el asunto Castañeda Gutman vs. México, aclara que no le compete ni a ella ni a la Convención el determinar «una modalidad específica o un sistema electoral particular», en referencia clara a ese margen de disponibilidad orgánico que tienen los Estados y sin el cual la propia concepción de soberanía, legitimadora al fin y al cabo de la Convención en cuanto que tratado internacional, no tendría sentido. En el caso Yatama vs. Nicaragua, párr. 206, la Corte expresamente afirma, con respecto al alcance del art. 23 de la Convención (derecho de participación política): «La aplicación y previsión de requisitos para ejercitar los derechos políticos no constituyen, per se, una restricción indebida a los tales derechos políticos. Éstos no son absolutos y pueden estar sujetos a limitaciones. Su reglamentación debe observar los principios de legalidad, necesidad y proporcionalidad en una sociedad democrática». Una interpretación tan extensiva como la que hace el Tribunal boliviano, dando por supuesto que la CIDH rechaza las limitaciones de mandato al pesar sobre ellas derechos como el de participación política, podría llevar al absurdo de declarar contraria a la convención las restricciones de edad para presentarse a las elecciones.

A mayor abundamiento, la Comisión Interamericana, en el famoso caso del dictador guatemalteco Ríos Montt (Informe n. ${ }^{\circ} 30 / 93$, caso 10.804, de 12 de octubre de 1993), recuerda en los considerandos 32 a 35 que las limitaciones constitucionales a la reelección, incluidas las inegibilidades que persigan un interés general como preservar la forma republicana de gobierno, son perfectamente compatibles con la Convención Interamericana y en ellas no puede entrar ni la Corte ni la Comisión a juzgar la decisión política, y democrática, que en su día tomara el constituyente.

Vemos, pues, cómo el control de convencionalidad es utilizado torticeramente por el Tribunal Constitucional de Bolivia, y referenciado tímidamente por los tribunales de Nicaragua y Honduras, para justificar la interpretación que él (y ellos) hace pero que nunca realiza, en ningún momento, la propia Corte Interamericana. La supremacía interpretativa de los derechos de participación e igualdad sobre la parte orgánica de la Constitución, anulando la 
virtualidad misma de esta en cuanto que limitación jurídicamente articulada al poder político, se potencia además en el caso boliviano mediante la servidumbre que le ofrece una cláusula de apertura hacia el derecho más favorable, aquí aplicada de manera subjetiva e injustificada.

\section{CONCLUSIÓN}

Como hemos tenido oportunidad de evidenciar a lo largo de las páginas que preceden, la cuestión del presidencialismo, sus defectos y virtudes, sigue constituyendo uno de los ejes de polémica en torno al que gira el devenir de las democracias constitucionales del continente americano. La limitación de mandatos fue pensada e ideada para poner fin a la histórica tendencia al caudillismo de unos líderes que, aupados al poder en el interior de unos sistemas excesivamente presidencialistas, terminaban desvirtuando estos y reduciendo sus posibilidades de existencia al autoritarismo o a la tiranía. A este límite se ha sumado, en los últimos años, la incorporación por parte del nuevo constitucionalismo latinoamericano de mecanismos como el revocatorio de mandato, que atenúan ostensiblemente las tendencias descritas y el propio hiperpresidencialismo al que parecía abocada la región. Aun así, la restricción principal y más efectiva en la evitación del continuismo sigue siendo, por su naturaleza drásticamente insoslayable, la limitación temporal de los períodos presidenciales.

Sin embargo, parece haberse iniciado un ciclo en América Latina contrario a esta previsión. Reformas constitucionales o nuevas constituciones han atenuado la limitación de mandatos o, directamente, han abierto la posibilidad de la reelección sine die. Referéndums o procesos constituyentes altamente participativos lo han respaldado con su legitimidad democrática, pero ha habido casos en que la ausencia de esta se ha intentado suplantar a través del uso desproporcionado de la justicia constitucional, la cual, aupada por las concepciones teóricas del neoconstitucionalismo, el garantismo y el control de convencionalidad, se ha erigido en espacio de decisión jurisdiccional donde la Constitución, supuesta norma valedora de su existencia, ha perdido la preeminencia. El caso boliviano es paradigmático: cómo un Tribunal Constitucional, utilizando de manera injustificada el control de convencionalidad y la cesión de jerarquía que establece la Carta Magna, ha terminado modificando explícitamente la configuración de los poderes del Estado y sus límites; hecho aún más grave por cuanto el pueblo boliviano, en uso de su soberanía, ya había sido llamado a referéndum para decidir sobre la reelección y había manifestado, inequívocamente, su rechazo.

El desborde de las funciones encomendadas a la justicia constitucional también se ha hecho notar en las decisiones de las Cortes de Costa Rica, Nica- 
ragua y Honduras. Aquí los argumentos se han centrado más en la posibilidad de que existan, en el seno de sus respectivas constituciones, verdaderas antinomias jurídicas que han de resolverse mediante una interpretación pretendidamente extensiva de los derechos fundamentales. Obviando, por un lado, que la Constitución es producto de un mismo poder constituyente y que todas sus previsiones tienen igual jerarquía, y por otro, el principio de especialidad por el que se admite en derecho la existencia de excepciones a los principios generales cuando vienen legitimadas y justificadas por la misma fuente de normatividad, las Cortes han declarado inaplicables las prohibiciones constitucionales de la reelección con argumentos, cuanto menos, polémicos. La asunción de jerarquías internas en la Constitución a través de los planteamientos de Bachof supone, en primer lugar, llevar a cabo un replanteamiento general de la propia concepción que de la Carta Magna y el poder constituyente se tiene, y en segundo lugar, realizar un verdadero ejercicio de prestidigitación por el que los jueces constitucionales se erigen en los intérpretes supremos no ya de la Constitución, sino de vagos principios iusnaturales o metapositivos que la superan y someten. La resolución de las pretendidas antinomias con base en tales postulados, y aun en la malinterpretación analizada de los planteamientos garantistas, se hace todavía más discutible cuando median, como el caso hondureño, cláusulas de intangibilidad, pues de admitirse la existencia de jerarquías en la Constitución estas deberían estar presididas por aquellas.

En definitiva, las sentencias aquí analizadas comparten una clara tendencia hacia el exceso de la función jurisdiccional de las Cortes Constitucionales, en lo que David Landau ha denominado como "constitucionalismo abusivo» (2013: 189-260); confunden en múltiples ocasiones soberanía y poder constituyente con la manifestación de la voluntad popular en las elecciones; asumen los ya de por sí polémicos postulados iusnaturalistas de autores como Bachof; malinterpretan el garantismo de Ferrajoli y la construcción doctrinal del núcleo indisponible, utilizan de manera sesgada el control de convencionalidad e incurren en contradicciones internas de imposible superación dialéctica. Y todo ello con un mismo objetivo y resultado: soslayar la voluntad constituyente para inaplicar las legítimas limitaciones de mandato que sus constituciones establecen. Los caminos al hiperpresidencialismo y a la crisis de la democracia y del constitucionalismo quedan, con ello, expeditos.

\section{Bibliografía}

Bachof, O. (2010). ¿`Normas constitucionales inconstitucionales? Lima: Palestra Editores.

Blanco Valdés, R. (2006). El valor de la Constitución. Madrid: Alianza Editorial. 
Carpio Marcos, E. (2000). Constitución y reelección presidencial: el caso peruano. Boletin Mexicano de Derecho Comparado, 98, 447-503.

De Vega, P. (2011). La reforma constitucional y la problemática de poder constituyente. Madrid: Tecnos.

Ellis, J. (2002). Founding Brothers, Revolutionary Generation. New York: Penguin Books.

Ferrajoli, L. (2011). Poderes salvajes. Madrid: Trotta.

García Belaunde, D. et al. (2017). El presidencialismo latinoamericano y sus claroscuros. Bolivia: Kipus.

García de Enterría, E. (1994). La Constitución como norma y el Tribunal Constitucional. Madrid: Civitas.

Gargarella, R. (2014). Latin American constitutionalism and the "engine room" of the Constitution. En P. Riberi y K. Lachmayer (eds.). Philosophical or political foundation of Constitutional Law?: perspectives in conflict (pp. 97-111). Madrid: Facultas.

Gómez Lugo, Y. y Mellado Prado, P. (1986). En torno a la posible inconstitucionalidad del apartado primero del artículo 57 de la Constitución española de 1978. Revista de Derecho Politico, 22, 175-195.

González Marrero, S. (2012). Las elecciones nicaragüenses de 2011. Anuario de Estudios Centroamericanos, 38,137-176.

Kelsen, H. (1974). La garantía jurisdiccional de la Constitución. México: Instituto de Investigaciones Jurídicas.

Landau, D. (2013) Abusive constitutionalism. University of California Davis Law Review, 1 (47), 189-260.

Lane Fox, R. (2007). El mundo clásico: la epopeya de Grecia y Roma. Barcelona: Editorial Crítica.

Linz, J. (1990). The Perils of Presidencialism. Journal of Democracy, 1, 51-60.

Linz, J. (1994). Presidential or Parliamentary Democracy: Does It Make a Difference? (pp. 3-87). En J. Linz y E. Valenzuela. The Failure of Presidential Democracy (pp. 3-87), The Johns Hopkins University Press.

Martínez Sospedra, M. (2011). La sombra del rey: el ejecutivo de 1812 y las primeras constituciones latinoamericanas. En A. Colomer Viadel (coord..). Las Cortes de Cádiz, la Constitución de 1812 y las independencias nacionales en América (pp. 141-173). Valencia: Universitat Politécnica de Valencia.

Martínez-Barahona, E. (2010). Las Cortes Supremas como mecanismo de distribución de poder: el caso de la reelección presidencial en Costa Rica y Nicaragua. Revista de Ciencia Política, 3 (30), 723-750.

McConnell, S. (2010). The Return of Continuismo? Current History, 109 (724), 74-80.

Noguera Fernández, A. (2010). La jerarquía constitucional de los tratados internacionales de Derechos humanos y la justiciabilidad de los derechos sociales. Nexos e interrelaciones en las últimas constituciones latinoamericanas. Revista del Ministerio de Trabajo e Inmigración, 87, 121-139. 
Oria, J. L. (1995). La reelección presidencial y la división de poderes. Buenos Aires: Abeledo Perrot.

Requejo Pagés, J. L. (2016). El sueño constitucional. Oviedo: KRK Ediciones.

Rivera Portillo, W. R. (2017). ¿Por qué en Honduras es ilegal la reelección presidencial? Adictos al poder. Tegucigalpa: OIM Editorial.

Rivera Santivañez, J. A. (2018). La inaplicabilidad de la Constitución para habilitar la reelección indefinida. En W. Herrera Añez (coord.). Los claroscuros de la acción de inconstitucionalidad que busca la ruptura del sistema constitucional boliviano (pp. 41-59). Cochabamba: Quipus.

Romero Pérez, J. R. (2015). Derecho constitucional y reelección presidencial. Sentencia del Tribunal Constitucional n. ${ }^{0} 2771$ del 2003. Revista de Ciencias Jurídicas, 136, 124-160.

Schmitt, C. (2011). Teoría de la Constitución. Madrid: Alianza.

Stern, K. (1987). Derecho del Estado de la República Federal Alemana. Madrid: Centro de Estudios Constitucionales.

Tovar Uricoechea, F. A. (2017). Sustitución constitucional y objeción democrática: una tensión aparente. Eunomía. Revista en Cultura de la Legalidad, 12, 62-76.

Treminio Sánchez, I. (2013). Las reformas a la reelección presidencial en América Latina. Estudios Sociológicos, 31 (91), 59-85.

Treminio Sánchez, I. (2016). ¿Cómo borrar la letra escrita en piedra? Norma pétrea y reelección presidencial en Honduras. Anuario de Estudios Centroamericanos. Universidad de Costa Rica, 42, 237-260.

Viciano Pastor, R. y Martínez Dalmau, R. (2011). El nuevo constitucionalismo latinoamericano: fundamentos para una construcción doctrinal. Revista General de Derecho Público Comparado, 9, 1-24.

Viciano Pastor, R. y Storini, C. (eds.). (2016). Innovación y continuismo en el modelo constitucional boliviano de 2009. Valencia: Tirant lo Blanch.

Zúñiga Urbina, F. y Cárcamo Tapia, F. (2015). ¿Inconstitucionalidad de normas constitucionales? Un caso de «constitucionalismo abusivo». Derecho Público Iberoamericano, 7, 219-237. 